\title{
Study on Flexural strength of RC Beams Using Polymer Infiltrated Steel Fiber Laminates
}

\author{
T.Pradeep ${ }^{*}$, C. Dhanendhra Prabhu ${ }^{2}$ \\ ${ }^{I}$ Assistant Professor, Department of Civil Engineering, KSRCT, 637215, Tamil Nadu, India. \\ ${ }^{2}$ Adhoc-Assistant Professor, Department of Civil Engineering, IRTT, Tamil Nadu, India. \\ *Corresponding author E-Mail ID: tpradeep1125@gmail.com \\ Doi: https://doi.org/10.34256/irjmtcon63
}

\begin{abstract}
An experimental investigation is made for strengthening of $\mathrm{RC}$ beams. This research is currently being focused on the use of correct material for repair and strengthening of existing reinforced concrete structure and the research is also concern about the effective utilization of aggregate in construction industry due to scarcity of natural resources. Strengthening can be done by using polymer which includes high steel fiber. Here crimpled steel fiber is used having $0.5 \mathrm{~mm}$ diameter and aspect ratio of 50. This study is meant for analyzing the flexural behavior of external bonded reinforced concrete beam. The external strengthening is need for increasing durability \& serviceability of the member. In total four number of beam specimens were casted and tested less than two points loading. Out of four specimens, one was conventional and for the next beam laminates bonded at bottom and beam bonded at bottom and lateral faces and beam laminated by all the four sides. The cross sectional dimension of beam $1100 \mathrm{~mm}$ x $100 \mathrm{~mm}$ x $150 \mathrm{~mm}$. Load deflection characteristics of the specimens were studied and energy absorption were calculated. An analytical model was created with ANSYS and the experimental results were compared with the software.
\end{abstract}

Keywords: Strengthening, Polymer, Steel fiber, Serviceability.

\section{INTRODUCTION}

Strengthening of concrete structures must be considered when the existing structure deteriorates or any alteration to the structure has to be made due to which the structure may fail to serve its purpose. Concerns must be taken to existing materials, often in deteriorated condition, loads during strengthening and to existing geometry.

\section{STRENGTHENING METHODS}

$\mathrm{RC}$ beams need to be strengthening when the existing steel bars in the beam are unsafe or insufficient, or when the loads applied to the beam are increased. In such case, there are different solutions are Fiber reinforced polymer, External post-tensioning, Section enlargement; Adding Steel Plates to the Beam are followed.

\section{LITERATURE REVIEW}

Farnam et al, (2010) investigated the Triaxial compressive behaviours of high strength concrete (HSC), HPFRC and SIFCON. Increasing of fiber volumes increases peak stress, energy absorption, toughness and Poisson's ratio. Shear failure occurred for HSC and HPFRC; whereas a 

combination of shear and crushing mode of failure was observed for SIFCON with $5 \%$ steel fibres. For SIFCON with $10 \%$ of steel fibre, only crushing mode of failure wasobserved.Samir Okba et al, (2017) investigated the properties of different types of polymer adhesives. All the polymers are exposed to four different temperatures are exposed with respect to time. After exposure the tensile and compressions test were tested. The elevated temperatures are 600, 1000, 1500 and 2000 and time of 1,2, 3 and 6 hours along with a specimen of room temperature is also tested. From the results the epoxy polymer has good behavior where the reduction of compression strength is by $33 \%$ at 1400 where other polymers the same strength is reduced at $800 \mathrm{C}$. The reduction of tensile strength is by $33 \%$ at $800-900 \mathrm{C}$ where other polymers the same strength is reduced at 600-700C. It is concluded that epoxy adhesive has higher resistance than other polymers. Murat Tuyan et al, (2012) experimentally investigated the effect of mix proportions of SIFCON matrix (slurry), curing conditions, aspect ratio of steel fiber, embedded length and fiber type on the single fiber pull-out behavior from SIFCON matrix was investigated. Test results indicated that fiber type, embedded length of fiber, curing conditions, fiber end condition, and matrix strength has a considerable effect on fiber-matrix bond. Increasing the diameter of the fiber and improving the curing conditions increased matrix-fiber bond. In addition, increasing bond strength was observed with increasing strength of SIFCON matrix. The pull-out toughness increased by increasing embedded length of fiber. It has been observed that hooked end fibers have shown better interface bond compared to the smooth fibers.

\section{MATERIAL PROPERTIES}

\subsection{Polymer Resin}

The success of strengthening technique primarily depends on performance of the Polymer resin used. Numerous types of resins with wide range of mechanical properties is commercially available in the market. The resin is prepared by mixing base agent and hardener.

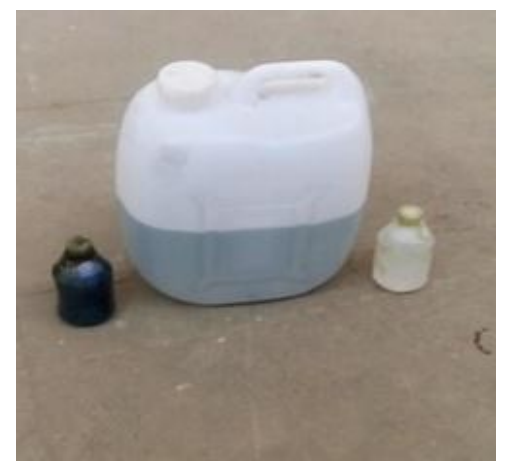

Fig 1 Polymer with Accelerator and Catalyst

These resins typically display low viscosity at room temperature (100-200 mPa.s) and are often referred to as reactive diluents. This Polymer contains polyurethane, acrylic, cyanoacrylate.

\subsection{Steel Fiber}

Crimppled steel fiber is used with diameter of $1 \mathrm{~mm}$ and length $50 \mathrm{~mm}$.

\section{PREPARATION OF SPECIMEN 4.1 Composite Laminates}

The laminate mat is prepared by infiltrating Polymers into the steel fibers into the mould of size $1100 \mathrm{~mm}$ X $100 \mathrm{~mm}$ X $5 \mathrm{~mm}$. The steel fibre is oriented in all directions i.e. perpendicular and parallel to load. The fiber mat is laminated over steel reinforcement bars. To improve the bonding strength GP resin is coated over the top surface of the fiber. Then the specimen is allowed to dry for 2- 3 days. The fiber gets bonded with steel bar then it is used as reinforcement 
bar in beam. While using GP resin accelerator and catalyst are mixed to improve the bonding strength and speeding up the process. First catalyst is added to the resin in the ratio of 1:100 and mixes it well using a glass rod. After ten minutes accelerate is added to mix in the ratio of 1:100 with the resin. After applying the accelerator mix should be applies as soon as possible or else it hardens and turns liquid in to solid state. Figure 2 shows the preparation of resin by mixing with accelerator and catalyst. Figure 3 shows the laminate plate preparation mould.

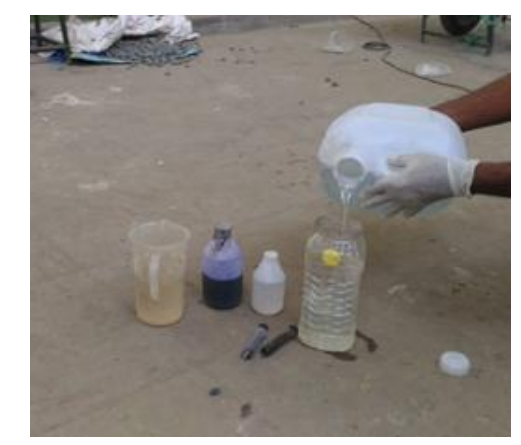

Fig 2: preparation of Resin

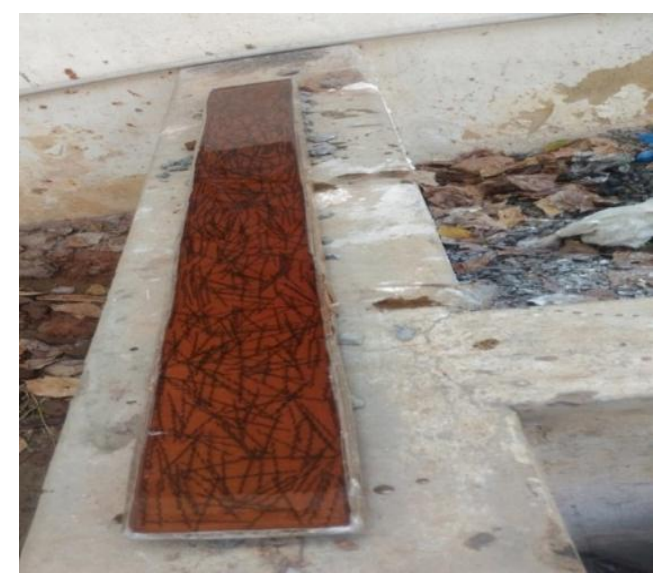

Fig 3. Resin infiltrated with Steel Fiber before hardening

\subsection{Casting of Beams}

Four beams have been casted. One was control beam and the other Three was composite beam. The beam is of size $1100 \mathrm{~mm} \times 150 \mathrm{mmx} 100 \mathrm{~mm}$. The two numbers of $10 \mathrm{~mm}$ diameter bars are provided as the main longitudinal reinforcement, two numbers of $8 \mathrm{~mm}$ diameter bars are provided as the hanger bar, and $8 \mathrm{~mm}$ diameter bars as stirrups at a spacing of $100 \mathrm{~mm}$. and curind is for 28 days. The detailing diagram of $\mathrm{RC}$ beam is shown in figure 4 . Table 1 shows the specimen ID with details of each specimen.

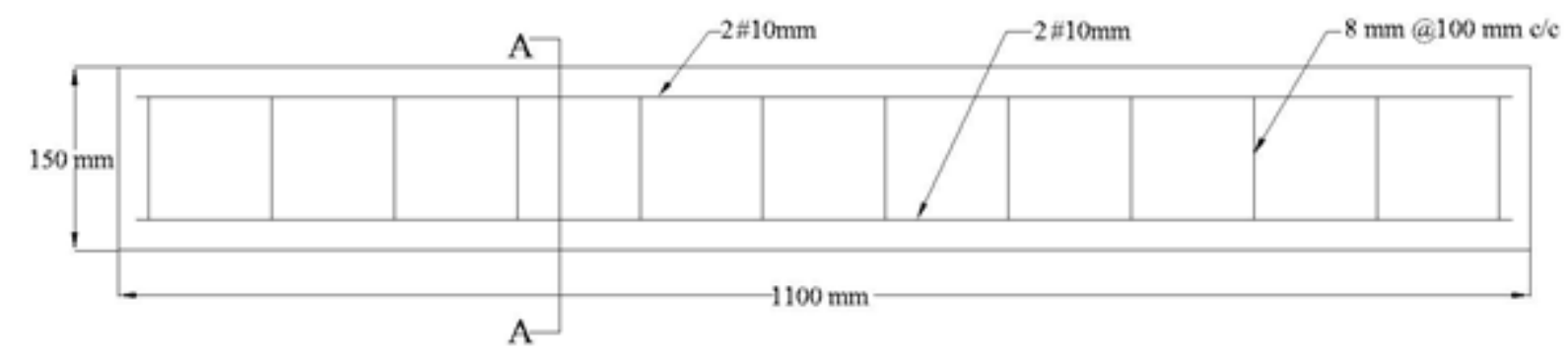




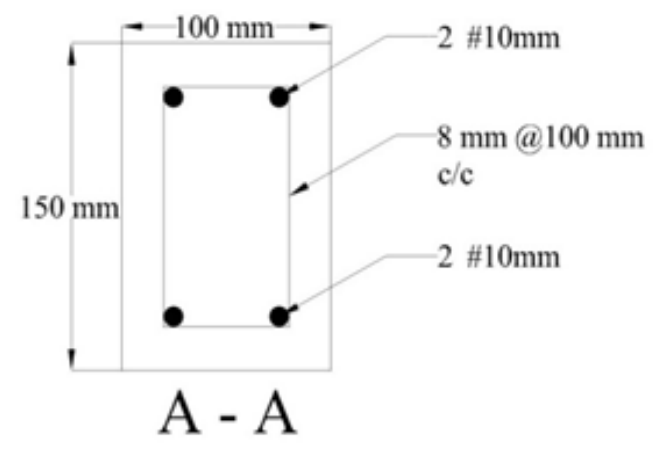

Fig 4. Beam Detailing

Table 1. Specimen ID With Details

\begin{tabular}{|c|c|c|}
\hline Sl.No & Specimen ID & Specimen Description \\
\hline 1 & CB & Control Beam \\
\hline 2 & B 1 & Laminates bonded at Bottom \\
\hline 3 & B 2 & Laminates bonded at Bottom and Side Faces \\
\hline 4 & B 3 & Laminates bonded at all sides \\
\hline
\end{tabular}

\subsection{BONDING OF COMPOSITE LAMINATES}

Four numbers of Composite laminates different steel fiber contents $(5,10,15$ and $20 \%$ by volume) of $5 \mathrm{~mm}$ thick are used for externally strengthening. The soffit of the prism and bonding face of laminates are cleaned to remove the dust particles and after surface preparation the resin mixed with catalyst and accelerator is applied on the prism and laminate. The Composite laminates already cast are placed over the specimen and held in position and the specimen is allowed to dry for 60 minutes. And this is repeated for the entire prism. The composite laminates bonded with prism is shown in figure 5.5 Curing time (air curing) required for epoxy resin is maximum of 4 hours and the temperature is less than $35^{\circ} \mathrm{C}$ but the test has been conducted after 2 days even though 4 hours of curing for resin is normally adopted.

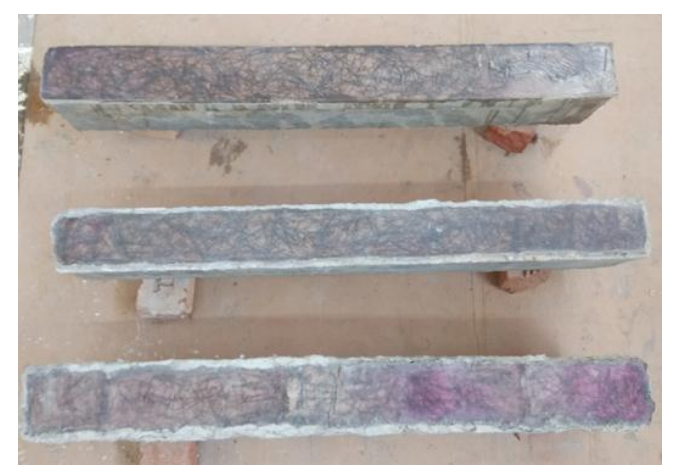

Fig 5. Beam bonded with Laminates

Laminates of size $1100 \mathrm{~mm} \mathrm{X} 100 \mathrm{~mm}$ X $5 \mathrm{~mm}$ is prepared for strengthening of beams. After the results of prism the optimum volume of fiber content is taken out and laminates with optimum fiber content is prepared, for strengthening. Laminates are bonded only on bottom side for one beam, bonded with bottom and lateral sides for another beam and laminates are bonded with all the four sides of the beam. Such that the beam is fully covered by laminates. 


\section{EXPERIMENTAL INVESTIGATION}

1

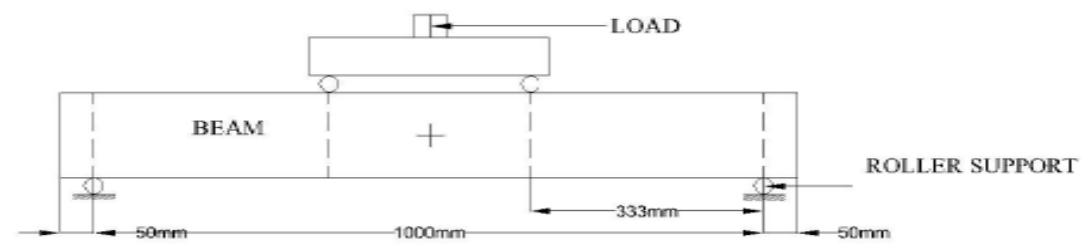

Fig 6. Experimental setup for beam

\subsection{Testing of Prism}

Four numbers of polymer composite laminates of size $500 \times 100 \times 10 \mathrm{~mm}$ for each prism. Volume fraction Vf $=5.0$ for A05, and Volume Fraction 10.0 percent for A10, and Volume Fraction 15.0 percent for A15, and Volume Fraction 20.0 percent for A20 were applied. The hand dispersion of steel fibers and grouting process are adopted. The prism specimens were tested after 28 days of water curing. For each ratio two specimens were and the average of the test result was compared. The flexural strength results were shown in the table 2.

Table 2:Modulus Of Rupture For Prism

\begin{tabular}{|c|c|c|c|}
\hline S.No & $\begin{array}{c}\text { SPECIMEN } \\
\text { ID }\end{array}$ & Percentage of Fiber & Modulus of Rupture (N/mm $\left.{ }^{\mathbf{2}}\right)$ \\
\hline 1 & AA & 0 & 4.56 \\
\hline 2 & A05 & 5 & 5.02 \\
\hline 3 & A10 & 10 & 5.41 \\
\hline 4 & A15 & 15 & 5.97 \\
\hline 5 & A20 & 20 & 5.02 \\
\hline
\end{tabular}

\subsection{Testing of Beams}

The gradual load was given to the specimens with the increment of $3 \mathrm{kN}$. The first crack load was noted when the formation of initial cracks was noted. The loading process continues till the final failure of the beam specimen. The load deflection histories for all the beams were recorded with the help of the data acquisition system, load cell.

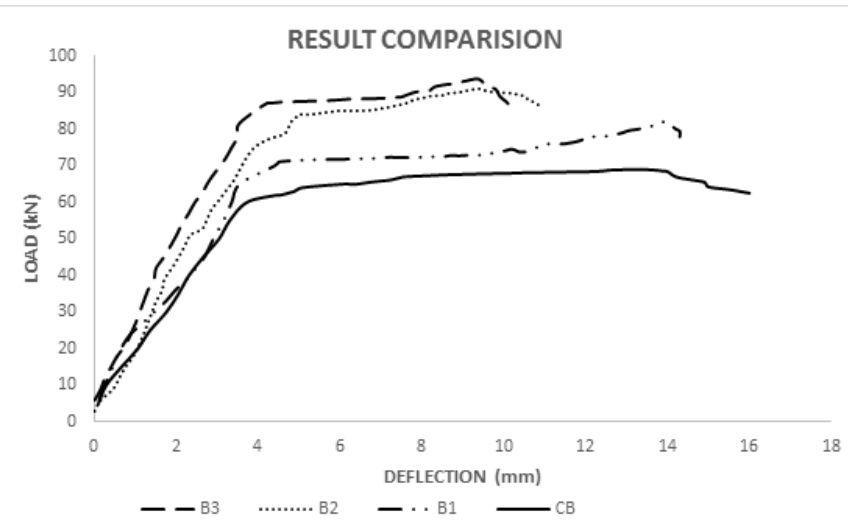

Fig 7. Load Deflection Curve 
From the load deflection curves it is noted that strengthened beams shows high flexural strength than conventional. The beam strengthened at bottom has light increase in flexural strength, where other two beams absorb more strength. The load deflection curve for all the four beams were given in figure 7 .

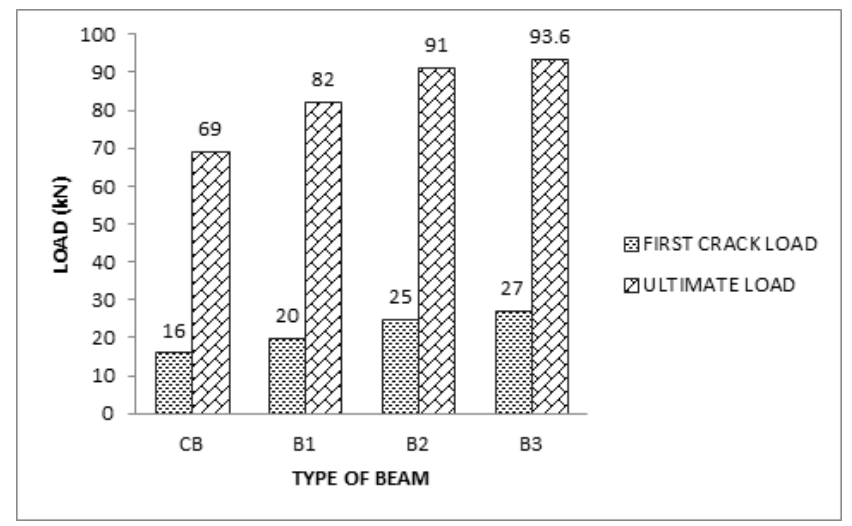

Fig 8. First Crack Load vs Ultimate Load

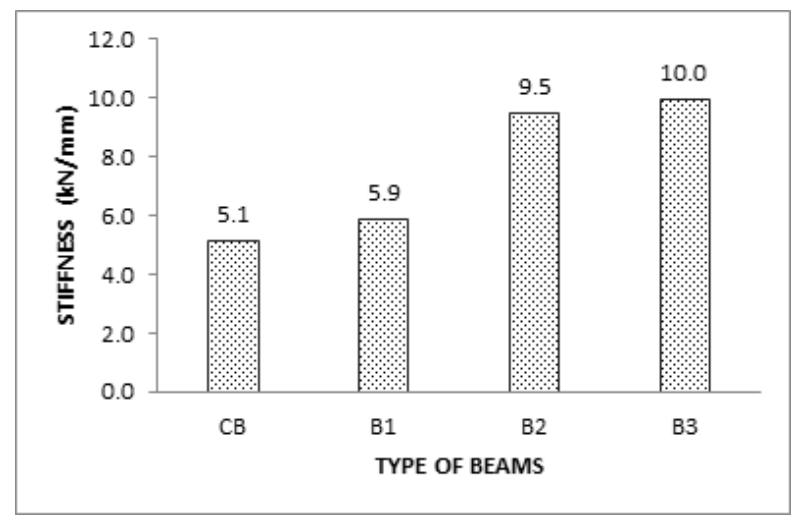

Fig 9. Stiffness for All Beams

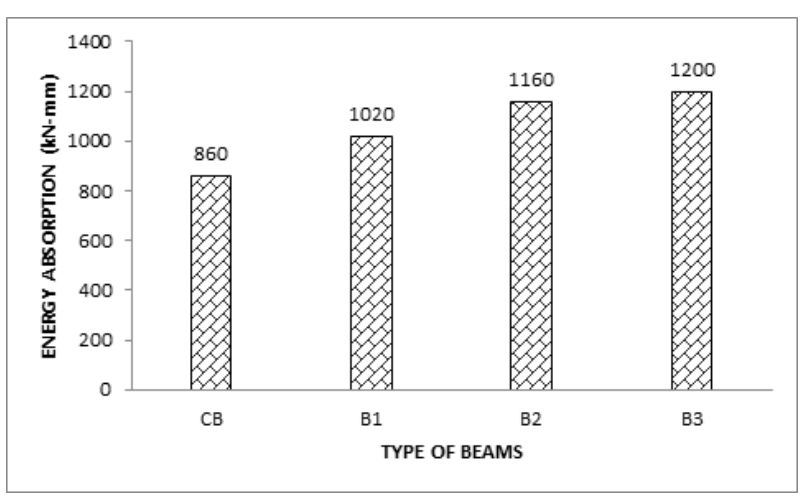

Fig 10.5 Energy Absorption For all Beams

\section{CONCLUSION}

The experimental results have demonstrated that both the flexural and the flexural-shear strengthening capacity of the RC beams increased using externally bonded laminates on bottom and/or lateral faces. From load-deflection curve, it was concluded that full-bonded laminates has shown good results in terms of its strength, ultimate load, stiffness and deflection compared to that of control specimen and strengthened by other laminates. The ultimate load for beams strengthened at bottom, at bottom and side \& at all four sides were $15.8 \%, 24.2 \% \& 26.2 \%$ 
T.Pradeep \& C. Dhanendhra Prabhu / International Research Journal of Multidisciplinary Technovation /2019, 1(6), 451-457 respectively greater than conventional beam. The deflection for the beams in the following order $\mathrm{CB}>\mathrm{B} 1>\mathrm{B} 2>\mathrm{B} 3$. The beam strengthened at bottom and lateral faces shows better performance in terms of strength factor and economy.

\section{REFERENCES}

1. Abdollahi M, M Bakhshi, Z Mirzaee, M Shekarchi, M Motavalli "SIFCON strengthening of concrete cylinders in comparison with conventional GFRP confinement method", Construction and Building Materials, Vol.36 pp.765-778,2012

2. AhsanollahBeglarigale, ÇaglarYalcınkaya, HuseyinYigiter, HalitYazıc "Flexural performance of SIFCON composites subjected to high temperature", Construction and Building Materials, Vol.104 pp.99-108,2016.

3. ArunAniyan Thomas, Jeena Mathews "Strength and behaviour of SIFCON with different types of fibers", International journal of civil engineering andtechnology, Vol.14 pp. 3031,2014

4. David R Lankard, "slurry infiltrated fiber concrete (SIFCON): properties and applications", Materials Research Society, Vol.4 2,1985.

5. Farnam, M Moosavi, M Shekarchi, S K Babanajad, A Bagherzadeh "Behaviour of Slurry Infiltrated Fibre Concrete (SIFCON) under triaxial compression", Cement and Concrete Research, Vol.40, pp.1571-1581,2010.

6. Jitendra Nana Sandanshiv, S. K. Dubey, Prof. S. S. Bachhav "Experimental Study on Retrofitted RC Beams with Externally Bonded SIFCON Laminates", International journal of advance research in science management and technology, Vol.2, Issue 5,2016.

7. K Soudki, T Alkhrdaji "Guide for the Design and Construction of Externally Bonded FRP Systemsfor Strengthening Concrete Structures”, Structures Congress,2010.

8. Leila Soufeiani, Sudharshan N. Raman, MohdZamin Bin Jumaat, Ubagaram Johnson Alengaram, "Influences of the volume fraction and shape of steel fibers on fiber reinforced concrete subjected to dynamic loading - A review", Engineering Structures, Vol.124, pp. 405417,2016

9. 9. Luccioni , F Isla , R Codina , D Ambrosini , R Zerbino ,G Giaccio , "Effect of Steel Fibers on Static and Blast Response of High Strength Concrete", International Journal of Impact Engineering, Reference: IE 2915,2017.

10. Michaël Guy Callens, IgnaasVerpoest, Larissa Gorbatikh "Ductility of steel fibre/epoxy composites in function of their microstructure", Composite Structures, Reference: COST $8801,2017$. 